PAPERS

\title{
The aetiology of oligomenorrhoea and/or hirsuties: a study of 467 patients
}

\author{
DAVID FERRIMAN \\ D.M., F.R.C.P.
}

\author{
ANTHONY W. PURDIE \\ F.R.C.P.(Glasg.), F.R.C.S.(Glasg.), \\ F.R.C.O.G.
}

Academic Centre, North Middlesex Hospital, London N18 1QX

\begin{abstract}
Summary
An analysis of 467 patients with oligomenorrhoea and/or hirsuties in respect to duration of the menstrual cycle, body hair growth, ovarian size and the presence of psychological factors has revealed some useful pointers to diagnosis in this syndrome. Some $70 \%$ probably suffered from polycystic ovarian disease. Hirsuties and post-pill amenorrhoea are strong pointers to such a diagnosis. Some $10 \%$ of the cases may have been psychogenic in origin and are notably found amoung non-hirsute patients with normal sized ovaries. Another $10 \%$ may have been physiological in nature. All other disorders accounted for no more than $10 \%$ of the cases. Anorexia nervosa and ovarian dysgenesis are particularly to be found among amenorrhoeic, non-hirsute patients with normal sized (or small) ovaries accounting for no less than $37 \%$ of this group in our series.
\end{abstract}

KEY WORDS: oligomenorrhoea, hirsuties, menstruation, ovaries.

\section{Introduction}

Rational therapy in any group of disorders depends upon good differential diagnosis. Recently considerable advances have been achieved in this respect in patients with oligomenorrhoea and/or hirsuties often associated with infertility (Hull, 1981). We here present an analysis of the causes and their relative prevalences in 467 such patients with respect to duration of the menstrual cycle, body hair growth, ovarian size and presence of psychological factors. Pointers to correct diagnoses are discussed.

\section{Patients and methods}

The 467 patients, drawn from a total of 689 seen with oligomenorrhoea and/or hirsuties, are those in whom ovarian size was determined at gynaecography or, in a few cases, laparotomy. It had been planned to undertake gynaecography in all, but this was not possible for a variety of reasons. These include withdrawal from follow-up, refusal of gynaecography, presentation at clinics elsewhere without facilities for gynaecography, and observation at medical clinics for other complaints. Gynaecography was not thought justifiable in older women with established fertility. Later pressure of work prevented gynaecography in some young single women. The great majority of patients, 453 or $97 \%$, were in the 15-35 age range, with extremes of 9 and 47 . The mean ages of those in the 15-35 range, were 24, 24, 25 and 23 respectively for the four main groups of patients shown in Table 1.

\begin{tabular}{|c|c|c|}
\hline $\begin{array}{l}\text { Ovarian } \\
\text { size }\end{array}$ & $\begin{array}{l}\text { Body hair } \\
\text { growth }\end{array}$ & $\begin{array}{c}\text { Number of } \\
\text { patients }\end{array}$ \\
\hline Enlarged & $\begin{array}{c}\text { Hirsute } \\
\text { Non-hirsute }\end{array}$ & $\begin{array}{r}222 \\
49\end{array}$ \\
\hline \multirow{2}{*}{$\begin{array}{l}\text { Normal } \\
\text { (or small) }\end{array}$} & Hirsute & 113 \\
\hline & Non-hirsute & 83 \\
\hline
\end{tabular}

The average duration of menstrual cycles was determined from basal temperature charts. Hair scores and ovarian indices were determined by methods already described (Ferriman and Gallwey, 1961; Ferriman and Purdie, 1965). Laparotomy with a view to wedge resection was performed in 12 patients with gynaecographically enlarged ovaries and polycystic ovarian disease (PCOD) was confirmed in all. Ovaries were of normal size but polycystic in 9 patients submitted to laparotomy elsewhere either before coming under our care or subsequently; laparotomy was undertaken, specifically for wedge resection in 6 , and in 3 others for 
menorrhagia, pelvic tumour and bilateral herniae, respectively. The presence of psychological disturbances was assessed routinely at an early stage by one of us (D.F.). These disturbances mainly involved stress and anxiety states (often associated with weight loss), frank anorexia nervosa or depression. The worst affected patients and all those with frank anorexia nervosa were referred to psychiatrists for further assessment and, where necessary, management. Excretion of 17-oxosteroid and, later, plasma testosterone levels were assayed in all hirsute patients. Pregnanetriol excretion was determined only on occasion and was always normal. Buccal smear examinations, pituitary fossa radiographs, follicle-stimulating hormone (FSH) excretion and, later, plasma levels, thyroid function tests and other more sophisticated assays for adrenal, pituitary and hypothalamic function were carried out only when deemed desirable. Prolactin assays did not become available until late in the study and were employed in a few patients only.

\section{Definitions}

Useful pointers towards diagnoses emerge when patients are classified as being oligomenorrhoeic or amenorrhoeic, hirsute or non-hirsute, and as having enlarged, normal-sized (or small) ovaries.

Patients were regarded as normomenorrhoeic when cycles ranged between 3-5 weeks, as oligomenorrhoeic when menstrual cycles lay between 5 weeks and six months, and amenorrhoeic when cycles were longer. They were defined as hirsute when body hair scores exceeded four and non-hirsute when less. Ovaries were defined as enlarged when ovarian indices exceeded 20, and normal-sized when less (Ferriman and Purdie, 1965); a small group with indices less than 10 were defined as small.

\section{Results}

The distribution of the 467 patients with regard to ovarian size and body hair score is shown in Table 1. Table 2 shows the menstrual pattern and presence of hirsutism in relation to the diagnosis reached. $\mathrm{Pa}-\frac{\mathrm{D}}{\mathrm{D}}$ tients with enlarged presumed polycystic ovaries are classified as suffering from PCOD. Patients in whom: aetiology is uncertain are classified as idiopathic.

\section{Psychological factors}

The prevalences of psychological factors in $\mathrm{pa}-\frac{\mathbb{}}{\Omega}$ tients with PCOD and idiopathic disorders, subdi $\frac{0}{\infty}$ vided according to the presence of hirsutism and amenorrhoea, are shown in Table 3 . Chi-squared tests show no significant differences between any of the normo/oligomenorrhoeic groups. The differenceso between the hirsute polycystic and all other amenor rhoeic groups are highly significant $(P<0.001$ for all); the differences between other amenorrhoeicy groups are not. The differences between normo/oli-os gomenorrhoeic and amenorrhoeic hirsute and non hirsute polycystic groups are also not significani$(P>0 \cdot 1)$. The differences between normo/oligome-o norrhoeic and amenorrhoeic idiopathic groups both hirsute and non-hirsute are however significante $(P<0.005$ and 0.01 respectively).

\section{Patients with anorexia nervosa and ovarian dysgenefis.}

All but one of these patients were amenorrhoexc, and all had normal sized (or small) ovaries. Eight nine $(89 \%)$ patients with anorexia nervosa were nơnhirsute, as were 14 out of $18(78 \%)$ of those with ovarian dysgenesis. These 22 patients constituted $38 \% \approx$ of the total of 58 amenorrhoeic non-hirsute patients $\stackrel{\square}{\mathbb{D}}$ with normal (or small) ovaries in the entire series. $\overrightarrow{\vec{B}}$

The prevalences of individual disorders in this series of patients are low. No patients were diagnosed as suffering from hypothyroidism nor organic hypo-z thalamic disease, though one with each was seen in 222 in whom gynaecography was not performed.

Eleven of 15 patients with post-pill amenorrhoea(73\%) had enlarged presumed polycystic ovaries Twelve had suffered from oligomenorrhoea before taking the pill.

TABLE 2. Analysis of 467 patients with regard to aetiology. Numbers of hirsute patients in brackets

\begin{tabular}{|c|c|c|c|c|c|}
\hline Classification & Normomenorrhoea & Oligomenorrhoea & Amenorrhoea & \multicolumn{2}{|c|}{ Totals } \\
\hline PCOD & $43(43)$ & $170(137)$ & $67(50)$ & 280 & $59 \%$ \\
\hline Idiopathic & $27(27)$ & $69 \quad(44)$ & 58 (29) & 154 & $32 \%$ \\
\hline Anorexia nervosa & & 1 & 9 (1) & 10 & $2 \%$ \\
\hline Ovarian dysgenesis & & & $18 \quad(4)$ & 18 & $4 \%$ \\
\hline Delayed puberty & & & 3 & 3 & $0.5 \%$ \\
\hline Premature menopause & & & (2) & 3 & $0.5 \%$ \\
\hline Amenorrhoea-galactorrhoea & & (1) & (3) & 5 & $1 \%$ \\
\hline Gonadotrophin-releasing hormone deficiency & & & 2 & 2 & $0.5 \%$ \\
\hline Pituitary and adrenal adenoma & & & (2) & 3 & $0.5 \%$ \\
\hline Totals & 70 & 242 & 166 & $478^{*}$ & $100 \%$ \\
\hline
\end{tabular}

*Eleven patients appear in more than one column due to changes in their menstrual pattern. 
TABLE 3. Prevalence of psychological disorders in hirsute and non-hirsute normomenorrhoeic/oligomenorrhoeic and amenorrhoeic patients with PCOD or disorders of idiopathic origin

\begin{tabular}{lcccccc}
\hline & \multicolumn{2}{c}{ Normo/Oligomenorrhoea } & & \multicolumn{2}{c}{ Amenorrhoea } \\
\cline { 2 - 3 } \cline { 6 - 6 } Group & $\begin{array}{c}\text { Psychological } \\
\text { factors present }\end{array}$ & Total & & $\begin{array}{c}\text { Psychological } \\
\text { factors present }\end{array}$ & Total \\
\hline $\begin{array}{c}\text { Polycystic } \\
\text { Hirsute }\end{array}$ & $16(9 \%)$ & 176 & & $4(9 \%)$ & 46 \\
$\begin{array}{c}\text { Polycystic } \\
\text { Non-hirsute }\end{array}$ & $7(21 \%)$ & 33 & & $6(38 \%)$ & 16 \\
$\begin{array}{c}\text { Idiopathic } \\
\text { Hirsute }\end{array}$ & $10(14 \%)$ & 71 & & $14(48 \%)$ & 29 \\
$\begin{array}{c}\text { Idiopathic } \\
\text { Non-hirsute }\end{array}$ & $5(21 \%)$ & 24 & $18(64 \%)$ & 28 \\
\hline
\end{tabular}

\section{The small ovary}

A group of patients with unusually small ovaries (indices less than 10) is of interest. Thirty such patients were invariably amenorrhoeic and infertile contrasting with those having higher indices in whom the duration of the menstrual cycle and prevalence of infertility were much more variable. No less than $50 \%$ (15) were suffering from a form of ovarian dysgenesis with normal female pheno-type and chromosomal pattern. The remaining patients were suffering from severe forms of primary or secondary ovarian failure, including delayed puberty, premature menopause, Turner's syndrome, anorexia nervosa, amenorrhoea-galactorrhoea, gonadotrophin-releasing-hormone (GnRH) deficiency, pituitary adenoma and post-pill amenorrhoea.

\section{Discussion}

Polycystic ovarian disease is clearly a quantitatively important disorder in this syndrome. Some $57 \%$ of the patients in this series had enlarged presumed polycystic ovaries. Moreover Smith, Steinberger and Perloff (1965) and Givens (1976) have shown that a substantial proportion of hirsute patients with normal sized ovaries have polycystic changes. The same may be true of non-hirsute patients; PCOD occurs in hirsute and non-hirsute forms which may be related (Ferriman and Purdie, 1979). Nine of our patients with normal sized ovaries (six hirsute, three non-hirsute) proved polycystic on laparotomy. The true prevalence of PCOD in our series may therefore be greater, maybe as high as $70 \%$. Furthermore, hirsuties is clearly a significant pointer to PCOD. No less than $67 \%$ of patients with hirsuties in this series had enlarged ovaries. Post-pill amenorrhoea is also a pointer to PCOD. Of the patients, eleven $(73 \%)$ had enlarged ovaries and 12 $(80 \%)$ had oligomenorrhoea before taking the pill. Our findings are similar to those reported by Beacons- field et al. (1974) who found 50 out of 55 patients with post-pill amenorrhoea to have enlarged ovaries and $50 \%$ with oligomenorrhoea before taking the pill. Some underlying disorder seems likely to be present in such patients. PCOD may not be the only determining factor but clearly it is an important one.

Aetiology in the idiopathic category is uncertain (by definition) but some likely explanations present. It is generally accepted that psychological disturbances (particularly those with associated weight changes) can affect the menstrual cycle, though it may be difficult to decide whether they are causal, contributory or coincidental in individual patients. Psychological factors were present in $19 \%$ of the patients analysed in Table 3 ( 80 out of 423 ) which would seem rather high in an unselected population. The prevalence in some of the groups was higher than in others. A psychogenic origin seems more likely in patients who are non-hirsute and have normal sized ovaries, particularly if they are amenorrhoeic. The bulk of anorexia nervosa patients possess similar features. Indeed if the numbers of patients with psychological factors and frank anorexia nervosa are combined they constitute $45 \%$ of all nonhirsute patients with normal sized ovaries and amenorrhoea (26 out of 58). It is difficult to assign a precise figure for the percentage of patients whose disorder is primarily psychogenic, but around $10 \%$ may not be too far from the truth. The role of psychological factors needs further consideration.

Other possibly common differential diagnoses are normal physiological variants of oligomenorrhoea (Haman, 1942; Marshall, 1963) and hirsuties (Ferriman and Gallwey, 1961). These diagnoses are largely by exclusion and it is difficult therefore to put a figure on their numbers, but they may account for around another $10 \%$ of our series.

All other causes account for only $7 \%$ of our series (Table 2). However, galactorrhoea is a poor marker for hyperprolactinaemia (Franks et al., 1975; Seppala et al., 1975), the prevalence of which would no doubt 
have been higher if prolactin assays had been available earlier, perhaps by as much as fourfold (Franks et al., 1975). Further, the cycle initiation defect, a recently delineated disorder, of possible hereditary origin, may be quantitatively important (Hull, 1981). Post-pubertal adrenal hyperplasia (a late onset 21-hydroxylase deficiency) is another possibility-not systematically looked for in our study. Judging from the paucity of reports in the literature it is not considered quantitatively important. The low prevalence of such disorders as hypothyroidism and organic adrenal, pituitary and hypothalamic disorders is noteworthy.

A tentative breakdown of causes under broad headings is suggested in Table 4.

TABLE 4. Tentative classification of major causes underlying syndrome of oligomenorrhoea and/or hirsuties under broad headings

\begin{tabular}{ll}
\hline Polycystic ovarian disease & $70 \%$ \\
Psychogenic & $10 \%$ \\
Physiological & $10 \%$ \\
All other causes & $10 \%$ \\
\hline
\end{tabular}

A substantial proportion of patients with anorexia nervosa and ovarian dysgenesis are amenorrhoeic, non-hirsute and have normal (or small) ovaries. Together they constitute $38 \%$ of patients with this combination of features ( 22 out of 58 ). The combination is therefore a strong pointer to the possible existence of one or other of these disorders. FSH assay and ovarian size determinations will assist in diagnosis.

\section{Acknowledgments}

We wish to thank the North East Metropolitan Regional Hospita Board and the North East Thames Regional Health Authority for:substantial support over the period of this study. We wish to than many colleagues at this and other hospitals for reference of patients. other colleagues for advice or assistance with investigations includi ing Dr K. Fotherby, Dr W.J. Irvine. Prof. V. H. T. James. Prof. Johno Landon. Dr J. Loraine and Prof. P. E. Polani. We thank Mrs Janet⿳亠口冋 Howe for statistical studies and Mrs Maureen Reynolds and Mrs Lyn Beale for secretarial help.

\section{References}

Beaconsfield, P.. Dick. R.. Ginsburg. J. \& Lewis. P. (1974) Amenorrhoea and infertility after the use of contraceptives $\vec{\omega}$ Surgery, Gynecology and Obstetrics, 138, 571.

FERRIMAN. D. \& GALLWEY. J.D. (1961) Clinical assessment of bod hair growth in women. Journal of Clinical Endocrinology, 21, 1440.3

FERRIMAN, D. \& PURDIE. A.W. (1965) Association of oligomenorrhoea. hirsuties and infertility. British Medical Journal. 2, 69.

FERRIMAN, D. \& PURDIE. A.W. (1979) The inheritance of polycystico' ovarian disease. Journal of Clinical Endocrinolog!'. 11, 291.

Franks. S., MurRay, M.A.F., JeQuier. A.M.. SteEle. S.J.. NABARRO. J.D.N. \& JACOBS. H.S. (1975) Incidence and signifi- cance of hyperprolactinaemia in women with amenorrhoea.음 Clinical Endocrinologi: 4, 597.

GIVENS. J.R. (1976) Hirsuties and hyperandrogenism. Advances in $\vec{c}$ Internal Medicine. Year Book Medical Publishers. Chicago. $21 \mathrm{~g}$ 221 Haman, J.O. (1942) The length of the menstrual cycle. American
Journal of Obstetrics and Ginecologi: 43,870.

HULL, M.G.R. (1981) Ovulation failure and induction. Clinics $\mathrm{gin}_{\overrightarrow{\mathrm{O}}}$ Obstetrics and Gynaecologi. 8, 219.

MARSHALl. J. (1963) Thermal changes in the normal menstrat: cycle. British Medical Journal. 1, 102.

Seppala. N., Hirvonen. E., Ranta. T.. Virkunnen, P. \& Leppal: OTO. J. (1975) Raised serum prolactin levels in amenorrhoea. British Medical Journal. 2, 305.

Smith, K.D.. Steinberger. E. \& Perloff. W.H. (1965) Polycystic مِ ovarian disease. American Journal of Obstetrics and Gynecolog! $: \mathbb{Q}$ 93, 994.

(Accepted 20 July 1982) 